\title{
Water network rehabilitation: A group decision-making approach
}

\author{
Danielle C Morais* and Adiel T Almeida \\ Federal University of Pernambuco, PO Box 7462, Recife-PE; 50630-970, Brazil
}

\begin{abstract}
Rehabilitation of water networks is a complex problem which may require a range of different water management actions, involving groups or institutions having differing objectives, responsibilities and interests, and requiring collaboration for conflict resolution. Group decision making can play a vital role in situations where multiple actors are involved, each having their own private perceptions of the context and the decision problem to be tackled. This paper proposes a group decisionmaking model based on an analysis of individual rankings, with the aim of choosing an appropriate alternative which is the best compromise of the points of view of the actors involved in the decision problem. An application with 4 influence groups was conducted based on the proposed method.
\end{abstract}

Keywords: group decision, individual preferences, water losses, leakage

\section{Introduction}

Municipal water supply infrastructure maintenance is very important for sustainable urban development. Mismanagement in this field can have serious consequences, such as water pipebursts, which result not only in disruption of the service but also in significant water losses. Water lost from potable water distribution systems remains a key problem facing not only developing but also developed countries throughout the world. A new challenge in water distribution management is how to achieve effective water utilisation and reduction of wastage, taking into account many different aspects, such as technical, social and environmental.

The problem of rehabilitation of water networks needs to be perceived as a process where multi-discipline actors have to invest money, time and physical and mental effort in order to use scarce financial resources in an adequate way, choosing a desired action to provide water in volumes sufficient to meet domestic, commercial and industrial demands, to recognized quality standards, without interruption and at appropriate pressure. However, supporting a group decision-making process becomes intensely difficult due to the different perceptions of the actors of the way in which the problem should be handled and the decision made (Matsatsinis et al., 2005).

When more than one individual participates in a decision process it is necessary to aggregate their information. In general, the 2 methods that have been found to be most useful are the aggregation of individual judgments and the aggregation of individual priorities (Forman and Peniwati, 1998). The former is used when the group is assumed to act together as a unit, and the latter when they are assumed to act as separate individuals expressing their own preferences. Nevertheless, the problem of rehabilitation of water networks involves groups or institutions with different objectives, responsibilities and interests. This

\footnotetext{
* To whom all correspondence should be addressed.

III +55 81 2126-8728 Ext. 205; fax: +55 81 2126-8728 ext 201; e-mail: dcmorais@ufpe.br

Received 16 May 2009; accepted in revised form 10 August 2010.
}

study is therefore focused on the second situation, where an individual is acting in his or her own right, with different value systems. Thus it is concerned with the resulting individual alternative rankings.

One of the fundamentals of the Water Resources National Politic (Brazilian Ministry of the Environment; MMA, 2006) is the decentralisation and participation of all in the water resource management process - civil society, the public sector and water resource users. Decisions in this field normally involve multidisciplinary decision makers, who commonly use a voting procedure as a means to reach a decision. However, a simple voting system does not guarantee a global result considering the preferences of all decision makers.

Various authors have studied the problem of aggregating individual preferences for group decision-making (Smith, 1973; Armstrong et al., 1982; Forman and Peniwati, 1998; Cook, 2006). In fact, the voting system is one of the most useful ways to achieve a 'social choice' (Sales, 2005), because voting is one of the decision-making alternatives which is able to reach a solution when the decision to be made implies a conflict of interests among group members.

One of the earliest works based on social choice is Essai sur l'application de l'analyse à la probabilité des décisions rendues à la pluralité des voix, developed by Marquis de Condorcet (1785). In this work, Condorcet argued that the majority opinion will very likely identify the decision that is objectively the best. Condorcet's argument was known as Condorcet's rule. Based on this rule, Condorcet created a procedure to aggregate individual preferences, verifying which option was preferred by the majority of the decision-makers (Young, 1988).

Another pioneer in social choice theory was the Chevalier Jean Charles de Borda (1781), who used a count which was related to the ranking of alternatives according to each individual's preferences. Borda also pointed out some defects of Condorcet's method. Borda argued that when there are many options, Condorcet's method can elect an option which was endorsed by only a small minority of the electorate (Young, 1988).

In such a context, a group decision should be understood 
as a junction of the individuals' interests; thus the purpose of the final result is to allow for the maximisation of members' group satisfaction. The best result can be considered as the one that guarantees the largest number of satisfied decision-makers. Individual decision-maker satisfaction is related to the degree to which the final decision result is adapted to individual intention.

In this study, a method of analysing individual rankings was applied, by tackling the choice problematic. Thus, the final result of a group decision should be the choice of the alternative which represents the collective intention, based on the ranking position of the chosen alternative with regard to individual points of view, allowing the largest number of decision-makers to be satisfied with the final result. This method of analysis of individual rankings for group choice is conducted in 4 steps.

This paper is organised as follows: firstly, the problem is structured and some concepts of water losses are discussed, identifying where and why they happen; secondly, the fundamentals of the group decision-making process using the method of analysis of individual rankings for group choice are presented, followed by an application of the method for water infrastructure rehabilitation. Finally, a summary and some concluding remarks are presented.

\section{The 'rehabilitation of water networks' problem}

One of the most important reasons to rehabilitate water networks is to reduce water losses. Leakage represents a significant portion of the high index of water losses found, and is one of the crucial issues to be dealt with in order to improve the efficiency and effectiveness of water supply services (Mackenzie and Seago, 2005). There are many causes of leakage and they are related to soil type, water quality, technology and materials used in network construction, operating pressure and age of the system, and the operation and maintenance practices followed (Arreguín-Cortes and Ochoa-Alejo, 1997). Losses from leakage can be severe, and may go undetected for months or even years. The larger losses are usually from burst pipes or from the sudden rupture of a joint, while smaller losses are from leaking joints, fittings, service pipes and connections. It is inevitable that leakage will vary from one part of the country to another. According to Morais and Almeida (2007a), factors such as traffic loading and ground movement will vary, and therefore it is very difficult to compare the success of leakage management in different areas.

It is thus necessary to adopt preventive measures, in order to reach a decision about a distribution system in a just way, which assists the customer fully, does not harm the environment and is coherent with the realities faced by the water company (Al-Rashdan et al., 1999). On the other hand, to reduce leakage to zero cannot be practical, because there are always many very small leaks which are neither practical to find nor economic to repair. It is unreasonable to expect a company to reduce leakage to below the economic level.

Nevertheless, the economic implications of leakage reduction are all too obvious. Water leakage not only involves unnecessary expense in pumping and treatment costs, but may also trigger premature investment to develop new sources or to expand system capacity to keep pace with increasing demand. Reductions in leakage will therefore result in lower annual operating costs and, furthermore, deferment of demand-related capital expenditure. However, it is difficult to find the right alternative to reduce leakage when many actors are involved, which is often the case with this kind of decision problem.
These actors can represent different departments of a water company (engineer department, financial department), different organisations (environmental agencies) or simply different stakeholders involved in a project (society, as spoken for by community representatives). Each actor usually has their own specific objectives (Cai et al., 2004).

Hence, a methodology is needed to help these actors to evaluate the potential actions, with regard to predefined criteria, while taking into account the characteristics of the specific system and evaluating the alternatives from the point of view of each different actor, considering financial, technical, environmental and social aspects.

\section{Analysis of Individual Rankings method}

Bouyssou et al. (2006) analysed a variety of voting systems: In some situations, the election is uninominal, where each voter votes for one candidate only. In this kind of election, each voter ranks all alternatives from best to worse, without ties, and when voting each voter votes for the alternative that he ranked in the first position. Supposing a set of 3 alternatives for a 100 -voter election, where 51 voters prefer alternative $a$ to $b$ and $b$ to $c$ (in short $a P b P c$ ) and 49 voters prefer $c$ to $b$ and $b$ to $a(c P b P a)$. It is clear that 51 voters will vote for $a$ while 49 will vote for $c$. Thus $a$ has an absolute majority and wins. However, almost half of the voters perceive $a$ as the worst one, and alternative $b$ seems to be a good compromise.

Bouyssou et al. (2006) therefore perceived that uninominal election combined with the majority rule allows a dictatorship of majority and does not favour a compromise. A possible way to avoid this problem is to ask the voters to provide their whole ranking instead of their preferred alternative. Hence, the task of the aggregation method is to extract from all these rankings the best alternative reflecting the preferences of the voters as much as possible. Following this idea, the method proposed in this paper seeks to study rankings of alternatives and to extract a choice of compromise, analysing the best and the worst alternatives classified by all decision-makers, applying 2 types of counting based on the principles of Borda's counting.

First of all, it is necessary to know how all the members of the group understand the problem situation and would solve it, making a ranking of actions (alternatives), which are evaluated by a family of criteria:

Let $A=\left\{A_{1}, A_{2}, \ldots, A_{i}\right\}$ be the set of alternatives, $g=\left\{g_{1}\right.$, $\left.\mathrm{g}_{2}, \ldots, \mathrm{g}_{\mathrm{n}}\right\}$ the consistent family of criterion and $\mathrm{DM}=\left\{\mathrm{DM}_{1}\right.$, $\left.\mathrm{DM}_{2}, \ldots, \mathrm{DM}_{\mathrm{m}}\right\}$ the decision-makers (DMs), who form the group. Each participant evaluates the problem with respect to the alternatives common to the group, constructing a rank order of the alternatives according to their individual preferences.

When one alternative is not chosen simultaneously by all decision-makers, it is necessary to apply a tool that makes the analysis of individual rankings possible, in order to find an alternative which can be considered the most appropriate for solving the problem, in accordance with all group members' points of view.

Based on ranking alternatives constructed by each member group, the procedure to apply the method proposed by Morais and Almeida (2007b) is well-defined in 4 exploration phases (Filter 1, Filter 2, Veto and Choose), as shown in Fig. 1.

With the individual ranks of all actors involved in the decision problem, the procedure of the analysis of individual priorities can start. It is important to note that the actors can apply any appropriate multicriteria method to support the ranking process. 


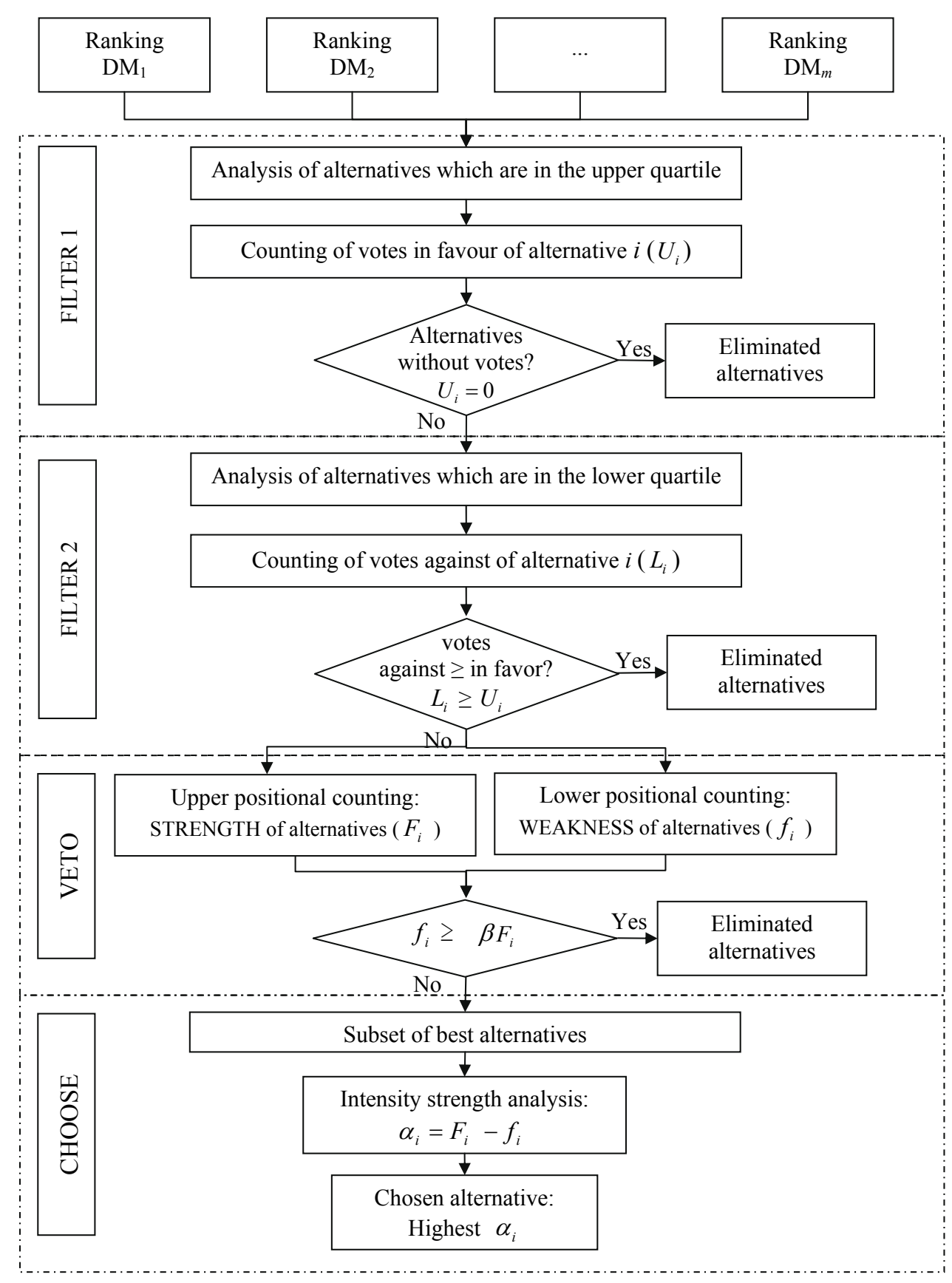

Figure 1

Overview of the proposed method

\section{Filter 1}

This first phase consists of creating a set of alternatives considered as a superior order, through application of separation by quartiles. The quartiles divide the sample of data into four equal parts in relation to the number of observations. They are used for convenience, when it is desired to eliminate the observed extreme values, or when it is desired to examine certain parts of the sample of data.

The data are then summarised for analysis of the alternatives constant in the upper quartile. The ranked set of alternatives is divided into two parts, where a quarter, or $25 \%$, of the alternatives are ranked in an upper position, and the remaining ones, three-quarters, or $75 \%$, are in a lower position. The element that indicates the position of the upper quartile is given by the following expression: $x=n / 4$, where $n$ is the total number of ranked alternatives (rounded up).

For $n=7 \rightarrow x=n / 4=1.75 \sim 2$ (rounding up), so the $2^{\text {nd }}$ position divides the ranking, where the $1^{\text {st }}$ and $2^{\text {nd }}$ positions make up the $25 \%$ of data falling within the upper quartile.

Those alternatives that are in the upper quartile would, theoretically, be the most appropriate alternatives to be implemented, translating the collective idea of the 'best' alternatives.

As part of the first phase, a count should be made of how many decision-makers preferred the alternatives that were in the upper quartile. The alternatives that did not obtain votes are eliminated from the process. In other words, those alternatives that did not appear among the best ones (in the group of the upper quartile) are taken out of the set of possible actions to solve the problem. 
Considering $U_{i}$ as the number of times that the alternative $i$ appears in the upper quartile, representing the number of votes this alternative received to be included among the best ones, $U_{i}$ can be computed by:

$$
U_{i}=\sum_{k=1}^{m} u_{i}^{\mathrm{k}} \quad \forall \mathrm{i}, \mathrm{k} \quad \forall \mathrm{j}=1, \ldots, \mathrm{x}
$$

where:

$$
u_{i}^{k}=\left\{\begin{array}{l}
1, \text { if the alternative } i \text { is in the upper quartile for the decision-maker } k \\
0, \text { otherwise }
\end{array}\right.
$$

$i$ corresponds to the alternatives in the upper quartile $(i=1, \ldots ; n)$

$j$ is the position in the upper quartile, varying from $1^{\text {st }}$ to $x^{\text {th }}$ $(j=1, \ldots, x)$

$k$ represents a decision-maker $(k=1,2, \ldots, m)$

The first filter is then concluded, eliminating those alternatives that were not considered by any of the decision-makers, in other words, $U_{i}=0$.

\section{Filter 2}

The second phase of the exploration is conducted by an inverse analysis, using the group of alternatives that compose the lower quartile. The element that indicates the position of the lower quartile is given by the following expression: $y=3 n / 4+1$ (truncate), where $n$ is the total number of ranked alternatives. In other words, it divides the ranked group of alternatives in 2 parts so that $25 \%$ of the alternatives are ranked in a lower position and the remaining ones, $75 \%$, are in an upper position.

A count should be made of how many decision-makers are against the alternatives. Considering $L_{i}$ as the number of times that the alternative $i$ appears in the lower quartile, representing the number of votes which this alternative received to be grouped among the worst ones, $L_{i}$ can be computed by:

$$
L_{i}=\sum_{k=1}^{m} l_{i}^{k} \quad \forall \mathrm{i}, \mathrm{k} \forall \mathrm{j}=\mathrm{y}, \ldots, \mathrm{n}
$$

where:

$$
\begin{aligned}
& l_{i}^{k}=\left\{\begin{array}{l}
1, \text { if the alternative } i \text { is in the lower quartile for the decision-maker } k \\
0, \text { otherwise }
\end{array}\right. \\
& i \text { corresponds to the alternatives in the lower quartile } \\
& (i=1, \ldots ; n) \\
& j \text { is the position in the lower quartile, varying from } y^{\text {th }} \text { to } n^{\text {th }} \\
& (j=y, \ldots, n) \\
& k \text { represents a decision-maker }(k=1,2, \ldots, m) .
\end{aligned}
$$

The alternatives with more votes against than in favour are eliminated, in other words, $L_{i} \geq U_{i}$. Those alternatives that were able to pass through both filters go on to the third phase of the exploration, termed 'veto'.

\section{Veto}

In the third phase, a positional count of the alternatives is accomplished, based on Borda's method (1781 in Cook, 2006). This method attributes a value corresponding to each position in the ranking, so that 1 point is added when moving from a particular position to the next higher one.

However, the method proposed here only analyses the situation of the alternatives which are in the upper and lower quartiles. Thus, to each position of the evaluation a number of points is attributed, differently from Borda's method. In this case, the number of points is computed as follows: 1 for the last position (the upper quartile limit: $x$ ), 2 for the next to last position, ...., $x$ for the first position. The points gained by each alternative are totalled and the alternatives obtain a score called Strength of the Alternative, $F_{i}$, given by:

$$
F_{i}=\sum_{k=1}^{m} \sum_{j=1}^{x}(x-j+1) q_{i j}^{k} \quad \forall \mathrm{i}, \mathrm{k} \quad \forall \mathrm{j}=1, \ldots, \mathrm{x}
$$

where:

$$
q_{i j}^{k}=\left\{\begin{array}{l}
1, \text { if the alternative } i \text { is in the position } \mathrm{j} \text { for the decision-maker } k \\
0, \text { otherwise }
\end{array}\right.
$$

$i$ is the remaining alternatives in the upper quartile, $j$ is the position varying from the $1^{\text {st }}$. position until the upper quartile limit $\left(x^{\text {th }}\right)$, for all $k$ decision-makers $(k=1,2, \ldots, m)$.

For instance, the Strength of the Alternative A is given by:

$$
\begin{aligned}
F_{A}= & (x)\left(q_{A 1^{s t .}}^{1}+\mathrm{q}_{\mathrm{Al}^{s t .}}^{2}+\ldots \mathrm{q}_{\mathrm{A}^{\mathrm{st} .}}^{\mathrm{m}}\right)+\ldots+(2)\left(\mathrm{q}_{\mathrm{A}(\mathrm{x}-1)^{t h .}}^{1}\right. \\
& \left.+\ldots+\mathrm{q}_{\mathrm{A}(\mathrm{x}-1)^{t h .}}^{\mathrm{m}}\right)+(1)\left(\mathrm{q}_{\mathrm{Ax}^{t h .}}^{1}+\ldots+\mathrm{q}_{\mathrm{Ax}}^{m} x^{t h .}\right)
\end{aligned}
$$

Similarly to the upper positional count, the lower positional count is made, where a number of points are attributed in an inverse way to each position of the evaluation, because higher points should be considered for the alternatives in the worst positions, thus guaranteeing that the weakest alternatives have a larger accumulation of points, in other words, votes against being favoured as alternatives. In this case, the attribution of points is computed as follows: $x$ for the last position, $(x-1)$ for the next to last position, ..., 1 for the first position (lower quartile limit: $y$ ). The points gained by each alternative are totalled and the alternatives obtain a score called Weakness of the Alternative, $f_{i}$, given by:

$$
f_{i}=\sum_{k=1}^{m} \sum_{j=y}^{n}(j-y+1) q_{i j}^{k} \quad \forall \mathrm{i}, \mathrm{k} \quad \forall \mathrm{j}=\mathrm{y}, \ldots, \mathrm{n}
$$

where:

$$
q_{i j}^{k}=\left\{\begin{array}{l}
1, \text { if the alternative } i \text { is in the position } j \text { for the decision-maker } k \\
0, \text { otherwise }
\end{array}\right.
$$

$i$ is the remaining alternatives in the lower quartile, $j$ is the position, varying from the first position of the lower quartile $\left(y^{\text {th }}\right)$ until the last position of the ranking $\left(n^{\text {th }}\right)$, for all $k$ decision-makers $(k=1, \ldots, m)$.

For instance, the Weakness of the alternative $\mathrm{A}$ is given by:

$$
\begin{aligned}
f_{A}= & (1)\left(q_{A y^{t h .}}^{1}+\ldots+\mathrm{q}_{\mathrm{Ay}}^{\mathrm{m}}\right)+(2)\left(\mathrm{q}_{\mathrm{A}(y+1)^{t h .}}^{1}\right. \\
& \left.+\ldots+\mathrm{q}_{\mathrm{A}(y+1)^{t h .}}^{\mathrm{m}}\right)+\ldots+(x)\left(\mathrm{q}_{\mathrm{A} n^{t h .}}^{1}+\ldots+\mathrm{q}_{\mathrm{A} n^{t h}}^{m}\right)
\end{aligned}
$$

Now, it is important to investigate if the intensity of that disagreement is enough to refuse that alternative. So, if $f_{i} \geq F_{i}$, it can be affirmed that there is a high opposition to the alternative being considered among the best ones; the alternative is then eliminated. In this phase, it is also possible to insert a more restrictive veto threshold, depending on the decision-makers, as follows:

$$
f_{i} \geq \beta F_{i}
$$

where:

$b$ represents the percentile of the $f_{i}$ value in relation to $F_{i}$ that the decision-makers are willing to accept. This value should be discussed between the analyst and the decision-makers. 
In this third filter, termed 'veto', the alternatives are also evaluated through a discordance meaning, to check if there is high opposition since the alternative is well-classified. Then, the veto threshold is introduced, representing not a specific performance of an alternative, but the difference between preferences among alternatives. This veto verifies if there is very high opposition in relation to the alternative selected by the second filter, the intention being to eliminate the alternatives classified as worst for the majority of the decision-makers, by the analysis of the Strength and the Weakness of the Alternatives, in other words, a positional analysis of the alternatives that are in the upper and lower quartiles.

For instance, if an alternative has the best positions considered by some decision-makers, but at the same time it is considered as worst by the other decision-makers, being classified significantly in worse positions than the ones considered in the upper quartile, it is probable that the alternative will pass filter 2 , but not the veto filter. Only when one alternative passes through all 3 filters can it be affirmed that this alternative translates a collective feeling, in other words, it is considered as a good alternative with regard to all decision-makers.

\section{Choose}

The fourth and last phase of the exploration is to choose the alternative. The procedure is concluded when the alternative that has the largest number of points is selected. This analysis of the intensity of the strength of the alternative is given by the expression:

$\alpha_{i}=F_{i}-f_{i}$, with the alternative chosen being that which presents the largest $\alpha_{i}$.

Nevertheless, in the case of ties (same scores), a pair analysis of those alternatives can be made, in order to verify which one is preferred by the majority of the decision-makers.

\section{Analysis of Individual Rankings for water supply infrastructure rehabilitation}

This section shows an application of the method to aid actors in choosing the action to be taken to rehabilitate the water distribution network. In order to illustrate the proposed method, the case study of Morais and Almeida (2007a) was used. The main characteristics of the case study are as follows: The city was located in the north-east of Brazil, in Pernambuco State. The population of the city is 45481 with a population density of 236.8 people $/ \mathrm{km}^{2}$. The city has a very hilly topography (varying from 60 to $130 \mathrm{~m}$ of elevation) resulting in large differences in water pressures along the network. The network distribution system is around 30 years old and there are many problems with meters. The water losses index is almost $60 \%$.

A list of 6 alternatives (actions to rehabilitate the water network infrastructure) is presented in Table 1.

Four actors were identified to integrate the decision process, representing 4 specific interests, as shown below (it is important to note that in decisions of this magnitude, all actors who have an influence in the decision process should be taken into account. The number of actors depends on how the decision will proceed (Table 2).

\begin{tabular}{|l|l|}
\hline \multicolumn{2}{|c|}{ Table 1 } \\
Single alternatives (Morais and Almeida, 2007a) \\
\hline Code & Alternatives \\
\hline $\mathrm{A}_{1}$ & $\begin{array}{l}\text { Increase metering: installation of large-scale and } \\
\text { small-scale meters. Water audits account for water } \\
\text { flow into and out of the distribution system (or part of } \\
\text { it), and they help to identify parts of the distribution } \\
\text { system that have excessive leakage. }\end{array}$ \\
\hline $\mathrm{A}_{2}$ & $\begin{array}{l}\text { Replacement of meters: avoiding over- and under- } \\
\text { registration (quantity of water registered by the meter } \\
\text { above or below the real flow). }\end{array}$ \\
\hline $\mathrm{A}_{3}$ & $\begin{array}{l}\text { Educational campaign to the customer: avoiding unau- } \\
\text { thorised use and helping the maintenance operation to } \\
\text { quickly find visible leakage or bursts. }\end{array}$ \\
\hline $\mathrm{A}_{4}$ & $\begin{array}{l}\text { Installation of pressure control valve: to reduce the } \\
\text { pressure in specific zones or hydraulic districts (HD). } \\
\text { A HD is a set of pipes that are interconnected within } \\
\text { a distribution network, with similar characteristics. } \\
\text { Each district may be isolated from a hydraulic point of } \\
\text { view, by closing all section valves. }\end{array}$ \\
\hline $\mathrm{A}_{5}$ & Rehabilitation of pipes and connections. \\
\hline $\mathrm{A}_{6}$ & $\begin{array}{l}\text { Use of acoustic equipment to locate leaks, in particu- } \\
\text { lar the small leaks. }\end{array}$ \\
\hline
\end{tabular}

\begin{tabular}{|l|l|}
\hline \multicolumn{2}{|c|}{ Table 2 } \\
Single decision-makers (Morais and Almeida, 2007a)
\end{tabular}

The decision-makers evaluate the alternatives, from their individual perspectives, points of view and interests, ranking the alternatives by importance. All DMs evaluate the problem considering the same 7 criteria (cost; benefit period; economicfinancial balance; effects in reduction of waste; environmental benefits; maintenance and operation conditions; social acceptability). They used the Promethee method (Brans et al., 1986) to rank the alternatives. Table 3 shows all individual results.

\begin{tabular}{|c|c|c|c|c|}
\hline \multicolumn{6}{|c|}{$\begin{array}{c}\text { Table 3 } \\
\text { Rankings of each decision-maker (Morais and } \\
\text { Almeida, 2007a) }\end{array}$} \\
\hline Ranking & $\mathrm{DM}_{1}$ & $\mathrm{DM}_{2}$ & $\mathrm{DM}_{3}$ & $\mathrm{DM}_{4}$ \\
\hline $1^{\text {st }}$ & $\mathrm{A}_{6}$ & $\mathrm{~A}_{6}$ & $\mathrm{~A}_{5}$ & $\mathrm{~A}_{3}$ \\
\hline $2^{\text {nd }}$ & $\mathrm{A}_{5}$ & $\mathrm{~A}_{1}$ & $\mathrm{~A}_{6}$ & $\mathrm{~A}_{5}$ \\
\hline $3^{\text {rd }}$ & $\mathrm{A}_{2}$ & $\mathrm{~A}_{5}$ & $\mathrm{~A}_{4}$ & $\mathrm{~A}_{4}$ \\
\hline $4^{\text {th }}$ & $\mathrm{A}_{1}$ & $\mathrm{~A}_{2}$ & $\mathrm{~A}_{3}$ & $\mathrm{~A}_{2}$ \\
\hline $5^{\text {th }}$ & $\mathrm{A}_{3}$ & $\mathrm{~A}_{4}$ & $\mathrm{~A}_{2}$ & $\mathrm{~A}_{1}$ \\
\hline $6^{\text {th }}$ & $\mathrm{A}_{4}$ & $\mathrm{~A}_{3}$ & $\mathrm{~A}_{1}$ & $\mathrm{~A}_{6}$ \\
\hline
\end{tabular}

As expected, the prioritised alternatives are not the same for each decision-maker. Thus, the results of the individual rankings go to the next phase of aggregation of the results, or global evaluation, where it is possible to analyse the individual rankings. 


\section{Analysis of individual rankings}

To conform with the first phase of the method, the alternatives which are in the upper quartile should be analysed. As the total number of alternatives, $n$, is 6 , then:

$$
\begin{aligned}
& \text { Element of location - Upper Quartile } x=\frac{n}{4}=\frac{6}{4}=1,5 \approx 2 \\
& \begin{aligned}
\text { Element of location - Lower Quartile } y & =\frac{3 n}{4}+1=\frac{3 * 6}{4}+1 \\
& =5,5 \approx 5
\end{aligned}
\end{aligned}
$$

\begin{tabular}{|c|c|c|c|c|c|}
\hline \multicolumn{5}{|c|}{$\begin{array}{c}\text { Table } 4 \\
\text { Set of alternatives in the upper and lower } \\
\text { quartiles }\end{array}$} & \multirow[b]{4}{*}{ Upper quartile } \\
\hline Ranking & $\mathrm{DM}_{1}$ & $\mathrm{DM}_{2}$ & $\mathrm{DM}_{3}$ & $\mathrm{DM}_{4}$ & \\
\hline $1^{\text {st }}$ & $\mathrm{A}_{6}$ & $\mathrm{~A}_{6}$ & $\mathrm{~A}_{5}$ & $\mathrm{~A}_{3}$ & \\
\hline $2^{\text {nd }}$ & $\mathrm{A}_{5}$ & $\mathrm{~A}_{1}$ & $\mathrm{~A}_{6}$ & $\mathrm{~A}_{5}$ & \\
\hline $3^{\text {rd }}$ & $\mathrm{A}_{2}$ & $\mathrm{~A}_{5}$ & $\mathrm{~A}_{4}$ & $\mathrm{~A}_{4}$ & \\
\hline $4^{\text {th }}$ & $\mathrm{A}_{1}$ & $\mathrm{~A}_{2}$ & $A_{3}$ & $\mathrm{~A}_{2}$ & \\
\hline $5^{\text {th }}$ & $\mathrm{A}_{3}$ & $\mathrm{~A}_{4}$ & $\mathrm{~A}_{2}$ & $\mathrm{~A}_{1}$ & \multirow[b]{2}{*}{ Lower quartile $\downarrow$} \\
\hline $6^{\text {th }}$ & $\mathrm{A}_{4}$ & $\mathrm{~A}_{3}$ & $\mathrm{~A}_{1}$ & $\mathrm{~A}_{6}$ & \\
\hline
\end{tabular}

The set of the alternatives in both quartiles is shown in Table 4 .

\section{Filter 1}

By considering Table 3, which shows the ranking per decisionmaker, the first phase can start, summing the number of decision-makers who are in favour of each alternative $\left(U_{i}\right)$, as

\begin{tabular}{|c|c|}
\hline \multicolumn{2}{|c|}{$\begin{array}{c}\text { Table } 5 \\
\text { Number of decision-makers in } \\
\text { favour of the alternatives }\left(U_{i}\right) \text { in the } \\
\text { upper quartile }\end{array}$} \\
\hline$I$ & $U_{i}$ \\
\hline$A_{1}$ & 1 \\
\hline $\mathbf{A}_{2}$ & 0 \\
\hline $\mathrm{A}_{3}$ & 1 \\
\hline $\mathbf{A}_{4}$ & 0 \\
\hline $\mathrm{A}_{5}$ & 3 \\
\hline $\mathrm{A}_{6}$ & 3 \\
\hline
\end{tabular}
given by Eq. (1). Table 5 shows the result of the sum of votes in favour of the alternatives.

Filter 1 is completed by eliminating the alternatives that are not in the upper quartile. Thus, alternatives $\mathrm{A}_{2}$ and $\mathrm{A}_{4}$ are eliminated.

\section{Filter 2}

The sum of the number of decision-makers who are against each alternative $\left(L_{i}\right)$ is calculated, as given by Eq. (2). The results are shown in Table 6.

\begin{tabular}{|c|c|}
\hline $\begin{array}{c}\text { Table } 6 \\
\text { Number of decision-makers against } \\
\text { the alternatives }\left(L_{i}\right) \text { in the lower } \\
\text { quartile }\end{array}$ \\
\hline $\mathrm{i}$ & $L_{i}$ \\
\hline $\mathrm{A}_{1}$ & 2 \\
\hline $\mathrm{A}_{3}$ & 2 \\
\hline $\mathrm{A}_{5}$ & 0 \\
\hline $\mathrm{A}_{6}$ & 1 \\
\hline
\end{tabular}

Filter 2 is completed by eliminating the alternatives with $L_{i} \geq U_{i}$, meaning that more decision-makers are against than in favour of the alternatives. Alternatives $\mathrm{A}_{1}$ and $\mathrm{A}_{3}$ are eliminated.

\section{Veto}

The remaining alternatives pass on to the process of upper positional counting, using Eq. (3). Tables 7 and 8, respectively, show the values obtained for $F_{i}$ and $f_{i}$.

Table 7

Upper positional counting: Strength of the alternatives $\left(F_{i}\right)$

\begin{tabular}{|l|c|c|c|}
\multirow{2}{*}{ ALTERNATIVES } & \multicolumn{2}{|l|}{$q_{i j}^{k}$} & \multirow{2}{*}{} \\
\cline { 2 - 3 } & $j=1^{\mathrm{st}}$ & $j=2^{\text {nd }}$ & \multirow{2}{*}{$F_{i}$} \\
\cline { 2 - 3 } & $(2-1+1)=2$ & $(2-2+1)=1$ & 4 \\
\hline $\mathrm{A}_{5}$ & 1 & 2 & 5 \\
\hline $\mathrm{A}_{6}$ & 2 & 1 & \\
\hline
\end{tabular}

\section{Table 8}

Lower positional counting: Weakness of the alternatives $\left(f_{i}\right)$

\begin{tabular}{|l|c|c|c|}
\hline \multirow{3}{*}{ ALTERNATIVES } & \multicolumn{2}{|l|}{$q_{i j}^{k}$} & \multirow{2}{*}{} \\
\cline { 2 - 3 } & $\mathrm{j}=5^{\text {th }}$ & $\mathrm{j}=6^{\text {th }}$ & \multirow{2}{*}{$f_{i}$} \\
\cline { 2 - 3 } & $(5-5+1)=1$ & $(6-5+1)=2$ & \\
\hline $\mathrm{A}_{5}$ & 0 & 0 & 0 \\
\hline $\mathrm{A}_{6}$ & 0 & 1 & 2 \\
\hline
\end{tabular}

\section{Choose}

In this phase, the strength intensity of the alternatives is calculated, i.e., $\alpha_{i}=F_{i}-f_{i}$. The alternative which has the highest number of points, or the highest a, is selected. Thus, it is verified that the alternative $\mathrm{A}_{5}$ has the best performance among the remaining alternatives, as $\alpha_{A_{5}}=4$.

For this specific study, the aggregation procedure provided a very satisfactory result. Although alternative $A_{6}$ was in the first position for $2 \mathrm{DMs}\left(\mathrm{DM}_{1}\right.$ and $\left.\mathrm{DM}_{2}\right), \mathrm{DM}_{4}$ ranked that alternative as least preferable. On the other hand, the alternative chosen, $\mathrm{A}_{5}$, was positioned at the top of only one individual ranking (ranking of $\mathrm{DM}_{3}$ ). However, $\mathrm{DM}_{1}$ and $\mathrm{DM}_{4}$ positioned alternative $\mathrm{A}_{5}$ in the second position and $\mathrm{DM}_{3}$ positioned that alternative in an acceptable position (third). Therefore, no DM feels that $\mathrm{A}_{5}$ is a bad alternative and the final result is considered to be very reasonable.

\section{Conclusions}

The real world is characterised by deep complexity, especially in decisions that involve society as a whole, as do all problems related to water. This happens because of the implications of the manner in which policy problems are presented and decision making is framed (Morais and Almeida, 2006). The problem of water supply infrastructure rehabilitation is very complicated, due to a lack of sanitation policies and a shortage of resources, in addition to the involvement of different actors with specific interests and conflicting objectives.

This paper presented a method, based on individual rankings, to assist actors involved in the process of rehabilitation of water networks to achieve a solution judged appropriate, ensuring that the majority of the actors are satisfied with the final result. This proposal considers that each individual of the 
group interprets a given situation in a different way, which can generate different decision-making models. Thus, this method starts from the ranking assigned by the individuals, and allows each participant to evaluate the problem based on the alternatives and criteria common to the group.

The tool of analysis of individual priorities is especially important in social decision making, particularly when one alternative is not chosen simultaneously by all decision-makers. It is then necessary to apply a tool that makes the analysis of individual rankings possible, in order to find an alternative which can be considered the most appropriate for solving the problem, in accordance with all group members' points of view.

This method has the potential to make a positive contribution to the process of water management, putting together the preferences of different groups of influence, while including criteria relying on interdisciplinary principles, such as technical, economic, environmental and social aspects and perceptions, and suggesting an option based on these evaluations and the relative importance of the decision-makers involved.

The use of this method, incorporated in the multicriteria model for group decision, allows groups to identify the alternatives for a solution that are more favourable for certain problems. It is important to note, that this method can be used to deal with many kinds of group decision-making problems.

With this methodology is possible to pay attention in several objectives that, probably, would not be noticed in a strictly technical-economic analysis. The method helps to improve the quality of decisions, by making the decision-making process more explicit, rational and efficient.

\section{Acknowledgements}

This work is part of a research programme funded by the Brazilian Research Council (CNPq). The authors would like to acknowledge the valuable suggestions that have been made by the editor and anonymous reviewers on a previous version of this paper.

\section{References}

AL-RASHDAN D, AL-KLOUB B, DEAN A and AL-SHERMMERI $\mathrm{T}$ (1999) Environmental impact assessment and ranking the environmental projects in Jordan. Eur. J. Oper. Res. 118 (1) 30-45.

ARMSTRONG RD, COOK WD and SEIFORD LM (1982) Priority ranking and consensus formation: The case of ties. Manage. Sci. 28 (6) 638-645.
ARREGUÍN-CORTES F and OCHOA-ALEJO L (1997) Evaluation of water losses in distribution networks. J. Water Resour. Plann. Manage. 123 (5) 284-291.

BORDA JC (1781) Mémoire sur les élections au scrutin, Histoire de l'Académie Royale des Sciences, Paris. In: Cook WD (2006) Distance-based and ad hoc consensus models in ordinal preference ranking. Eur. J. Oper. Res. 172 369-385.

BOUYSSOU D, MARCHANT T, PIRLOT M, TSOUKIAS A and VINCKE P (2006) Evaluation and Decision Models with Multiple Criteria: Stepping Stones for the Analyst. Springer, New York.

BRANS J, VINCKE P and MARESCHAL B (1986) How to select and how to rank projects: The PROMETHEE method. Eur. J. Oper. Res. 24 228-238.

CAI X, LASDON L and MICHELSEN AM (2004) Group decision making in water resources planning using multiple objective analysis. J. Water Resour. Plann. Manage. 130 (1) 4-14.

CONDORCET M (1785) Éssai sur l'application de l'analyse à la probabilité des décisions rendues à la pluralité des voix, Paris: De l'imprimirie. In: Yong HP (1988) Condorcet's theory of voting. Am. Polit. Sci. Rev. 82 (4) 1231-1244.

COOK WD (2006) Distance-based and ad hoc consensus models in ordinal preference ranking. Eur. J. Oper. Res. 172 369-385.

FORMAN E and PENIWATI K (1998) Aggregating individual judgments and priorities with the Analytic Hierarchy Process. Eur. J. Oper. Res. 108 165-169.

MACKENZIE R and SEAGO C (2005) Assessment of real losses in potable water distribution systems: some recent developments. Water Sci. Technol.: Water Supply 5 (1) 33-40.

MATSATSINIS N, GRIGOROUDIS E and SAMARAS A (2005) Aggregation and disaggregation of preferences for collective decision-making. Group Decis. Negotiation 14 217-232.

MMA (MINISTRY OF THE ENVIRONMENT) (2006) Plano Nacional de Recursos Hidricos: Panorama e estado dos recursos hídricos do Brasil, Vol. 1, edited by Ministry of the Environment, Brasília, Brazil.

MORAIS DC and ALMEIDA AT (2006) Water supply system decision making using multicriteria analysis. Water SA 32 (2) 229-235.

MORAIS DC and ALMEIDA AT (2007a) Group decision-making for leakage management strategy of water network. Resour., Conserv. Recycling 52 441-459.

MORAIS DC and ALMEIDA AT (2007b) Analysis of individual priorities for group decision-making. GDN 2007 - Group Decision and Negotiation Meeting, 14-17 May 2007 Mt. Tremblant, Canada.

SALES CV (2005) As mascaras da democracia: nota sobre a teoria democrática contemporânea à luz dos eixos Dahlsianos, Revista de Sociologia e Política 24 233-245.

SMITH JH (1973) Aggregation of preferences with variable electorate. Econometrica 41 (6) 1027-1041.

YOUNG HP (1988) Condorcet's theory of voting. Am. Polit. Sci. Rev. 82 1231-1244. 
